\title{
Experimental Research on the Bearing Capacity of the Widening Segment of Precast Small Box Girder
}

\author{
Liqiao Xia ${ }^{1, a}$, Qian $\mathrm{Li}^{2, a,{ }^{,}, \text {Han Ding }}{ }^{2, \mathrm{~b}}$ and Zengshun Tian ${ }^{3, \mathrm{c}}$ \\ ${ }^{1}$ Wenzhou Highway Investment Co., Ltd, Wenzhou, China \\ ${ }^{2}$ Research Institute of Highway Ministry of Transport, Beijing, China \\ ${ }^{3}$ Shandong Provincial Communications Planning and Design Institute, Jinan, China \\ a601060901@qq.com, b1143094892@qq.com, c1262820484@qq.com
}

\begin{abstract}
Keywords: Precast Small Box Girder, Splicing Technology, Segment Experiment, Shear Value, Deflection Difference
\end{abstract}

\begin{abstract}
Widening the existing expressway is an important way to solve the problems like road traffic congestion and level of service declining in the existing highway network. Besides, for the highway with large traffic volume and lack of detour roads, it is inevitable to open to traffic at the same time of construction. Taking a $20 \mathrm{~m}$ precast small box girder bridge widening project as the research object, the ABAQUS finite element entity model of the whole bridge and full-scale segment experiment is established, and the boundary conditions and loading force values of the segment model are determined by the similarity analysis. The numerical simulation calculation of the deflection difference between both sides of the joint and the joint reinforcement strain of the full-scale segment test model is performed, and results are compared with the experimental measured values, so as to verify the rationality of the finite element model. Moreover, this research further studies the shear transfer mechanism and bearing capacity of concrete joints with the finite element calculation, and the force-displacement curve of concrete joint loading in whole process is calculated. According to results, the early strength of concrete develops rapidly, while the deflection difference on both sides of the joint drops rapidly, and the deflection difference basically remains unchanged after 8 hours of casting. The shear transfer of joint concrete in the overall analysis model and section test model develops rapidly in the early stage, since then tends to be stable gradually. Results of the bearing capacity test describe that when the bottom reinforcement of the joint reaches the tensile strength and the deflection of the joint increases rapidly, the ultimate bearing capacity could be reached, and the most unfavorable part of the test joint could bear 17 times of 55t wheel load. It is demonstrated that the traffic control scheme of closing and widening the joint adjacent to the lane in the first three days could ensure the reliable casting performance of the concrete joint when the traffic is not interrupted. The research results would provide technical guidance for the design and construction of the same type of bridge.
\end{abstract}

\section{Introduction}

With the rapid development of economy, the existing road network could hardly support the rapid growth of traffic volume. In order to relieve such huge transportation pressure, the government not only constructs new freeways, but widens and reconstructs the existed freeways with large traffic volumes to increase the traffic capacity as well, such as Shanghai-Nanjing Freeway, Shanghai-Hangzhou-Ningbo Freeway and Shenyang-Dalian freeway ${ }^{[1]}$. As is known to all, the reconstruction project would inevitably have negative effects on normal operation of road sections to be widened. Therefore, it is of great social and economic benefits to explore the construction quality of bridge widening project under the condition of uninterrupted traffic, establish 
reasonable traffic control schemes and verify the reliability of concrete joint casting under traffic load.

For the construction technology of bridge widening, domestic and foreign scholars have carried out a lot of experimental and theoretical researches ${ }^{[2-6]}$. Under the traffic load, the deflection difference changes with time at the joint between new and old bridges, which is bound to affect the quality and strength of joint concrete casting in construction. According to the investigation of the completed bridge widening project, the interface between old and new concrete is likely to appear early cracks, leading to the weakening of lateral connection and the reduction of overall structural stiffness, which could affects the traffic safety and the beauty of the bridge deck seriously, and increase the maintenance and repair costs in the later stage.

In this paper, the 1-meter segment of the precast small box girder is selected as the experimental object. The 5-axis 55t vehicle is applied and the most unfavorable loading is determined. Based on that, the whole process of construction maintenance loading is simulated. The deflection difference between the two sides of the joint and the strain of the reinforcement in the joint of the full-scale segment test model are simulated and compared with the experimental data, so as to verify the rationality of the finite element model. Moreover, through the finite element calculation, the shear transfer mechanism and bearing performance of concrete joint are studied in further, and the force-displacement curve of the whole process of concrete joint loading is calculated.

\section{Traffic Organization Scheme During Construction}

During the widening construction under traffic serving conditions, in order to ensure the quality of joint concrete casting and reduce the maximum deflection difference on both sides of wet joint, the most simple and effective way is to implement traffic control. The proposed traffic control in the reconstruction project in this paper is shown in Table 1, which is performed by closing the lane adjacent to the widening joint.

\section{Table 1 Traffic organization scheme}

\begin{tabular}{lll}
\hline No. & With traffic control & Without traffic control \\
\hline Description & $\begin{array}{l}\text { The lane adjacent to the closed and widened } \\
\text { joint is used as the construction working } \\
\text { surface together with the emergency lane, and } \\
\text { the rest lanes are open to traffic and bear the } \\
\text { standard lane load }\end{array}$ & $\begin{array}{l}\text { All two lanes of the old bridge are open to } \\
\text { traffic and bear the standard lane load. The } \\
\text { emergency lane of the old bridge is used as } \\
\text { the construction working surface }\end{array}$ \\
Diagram &
\end{tabular}

Traffic control is implemented in the first three days of the reconstruction project. The lane adjacent to the joint and the emergency lane are used as the construction working surface, and the rest lanes are open to traffic and bear the standard lane load.

\section{Mechanical Performance Analysis}

Project Overview

The total length of an overpass is $8.7 \mathrm{~km}$, and most of the superstructure adopts prestressed concrete simply supported small box girder with standard span of $16 \mathrm{~m}$ and $20 \mathrm{~m}$, with continuous 
deck. Bridge widening design complies with the principle of "old bridge old standard, new bridge new standard", and the standard cross section of the new and old small box girder bridge is shown in Figure 1.

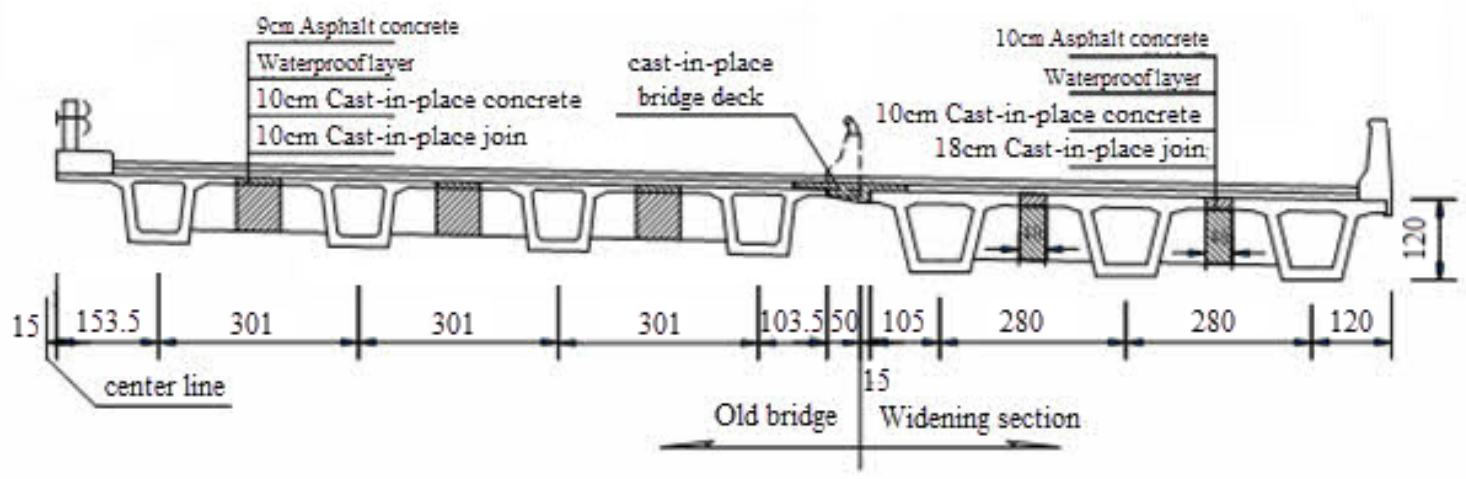

Fig. 1 Standard cross section of small box girder bridges widening (unit: $\mathrm{cm}$ )

The widening design scheme of precast small box girder bridge is described as below:

(1) The Superstructures are connected, while the substructures are separated. The wing plate at the joint of new and old box girder adopts rigidity connection, and the lower structure cap beam is not connected.

(2) The side of the new bridge is assembled by three $20 \mathrm{~m}$ small box girders. The height of single small box girder is $1.2 \mathrm{~m}$, and the transverse center distance of adjacent small box girders is $2.8 \mathrm{~m}$.

(3) The new and old box girders are only connected by flange plates without end diaphragms.

(4) Cut off $50 \mathrm{~cm}$ wing slab concrete of guardrail and side beam of old bridge, retain internal reinforcement, and reserve reinforcement for wing plate of new bridge edge beam.

(5) The transverse center distance of the box girder on both sides of the joint is $2.735 \mathrm{~m}$, the width of wet joint being $75 \mathrm{~cm}$, and the thickness changes from $28 \mathrm{~cm}$ on the new bridge side to $20 \mathrm{~cm}$ on the old bridge side.

\section{Establishment of Finite Element Model}

The overall model of the widening bridges is shown in Figure 2. The precast small box girder bridge is mainly composed of four parts: asphalt pavement, concrete pavement, prefabricated small box girder and rubber bearing. Binding constraints are applied between asphalt pavement and concrete pavement, concrete pavement and main beam, and between main beam and support, that is, the main and secondary surfaces are not separated in the analysis process. The diagram of full-scale segmental test model is shown in Figure 3.
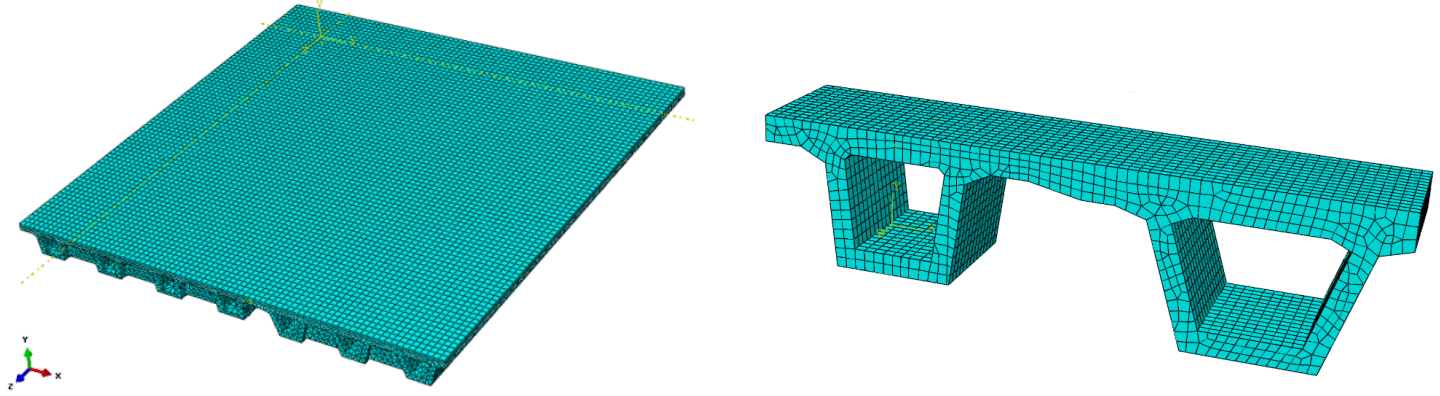

Fig. 2 Finite element model Fig. 3 Diagram of full-scale segmental test model

Determination of Boundary Conditions for Full Scale Segmental Test Model 
Midas Civil software is used to build old bridge model. The regulations of axle load of 5-axle total with 55-ton weight should be referred to the general design specification for highway bridges and culverts in $1989^{[7]}$, together with the longitudinal and horizontal arrangement of vehicle fleet. Based on that, the most disadvantageous loading position of vehicle load with or without traffic control scheme could be determined by the unique moving load tracker function. The load distributions under and without traffic control are shown in Figure 4 and Figure 5.

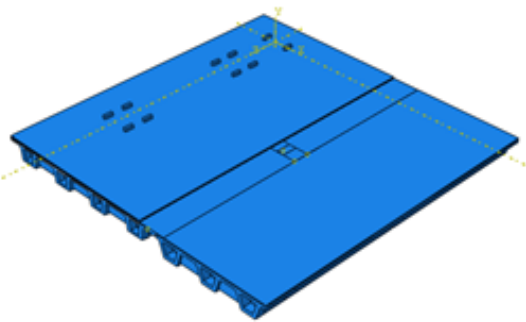

a) under traffic control

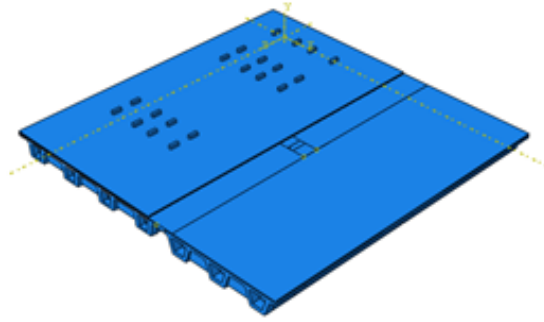

b) without traffic control

Fig. 4 Load distribution under two traffic control schemes

Considering the most unfavorable loading case, the deflections of the mid-span on the widened side of the old bridge under traffic control schemes and without control are $1.822 \mathrm{~mm}, 4.893 \mathrm{~mm}$ respectively.

In the full-scale segment model test, the loading force of the old bridge box girder is used as the control indicator to carry out cyclic loading. The joint concrete is loaded in two working conditions for five days. For the first working condition, the joint concrete is loaded for three days under traffic control, and for the second condition, the joint concrete is loaded for two days without traffic control.

According to the results of finite element calculation, the peak value of load force in the first working condition is $10 \mathrm{kN}$, and the corresponding deflection value of the old bridge box girder under independent state is $2 \mathrm{~mm}$. Then the rain flow method is used to collect the loading period and time of the real bridge. The loading period is defined as $12 \mathrm{~s}$, and the loading time of each cycle is $2 \mathrm{~s}$. The loading mode is shown in Figure 5.

After the traffic control is terminated, the bridge is loaded in different levels. The level and frequency of loading force in the second working condition are: loading $26 \mathrm{kN}$ for 6 times $/ \mathrm{h}, 20 \mathrm{kN}$ for 24 times $/ \mathrm{h}, 15 \mathrm{kN}$ for 46 times $/ \mathrm{h}, 10 \mathrm{kN}$ for $78 \mathrm{times} / \mathrm{h}$, and $5 \mathrm{kN}$ for 146 times $/ \mathrm{h}$. According to the sampling frequency of the real bridge in field, the loading period is $12 \mathrm{~s}$, and the loading time of each cycle is $2 \mathrm{~s}$. The diagram of loading mode is shown in Figure 6. 

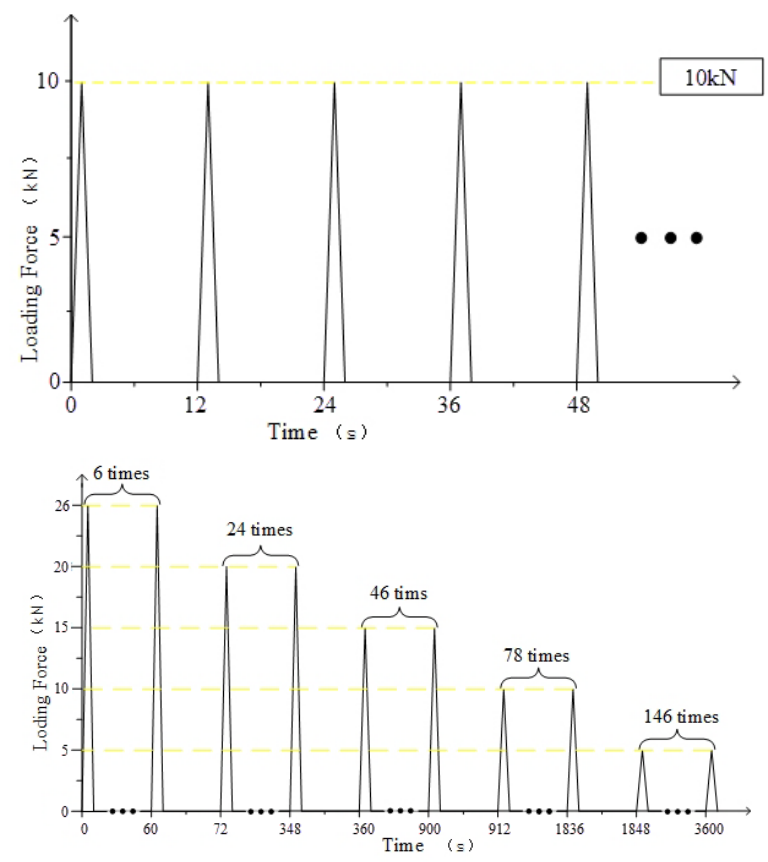

Fig. 5 Loading mode under traffic control Fig. 6 Loading mode after releasing traffic control

The new bridge part of the test component is pre-pressed with I-beam, and then connected with the pedestal by screw. Spring supports are installed at the bottom of some beams on old bridges. The electro-hydraulic servo loading system generates the loading force and allows the vertical displacement of the box girder, so as to simulate the dynamic deflection of real bridge. The layout of the overall model is depicted in Figure 7.

After repeated calculation, the results show that the shear force and bending moment of the whole and segment models are equivalent well with the development age of joint concrete, when the spring stiffness of bearing $\mathrm{K}=1.373 \times 10^{6}(\mathrm{~N} / \mathrm{m})$. Based on the spring stiffness, the loading forces before and after traffic control is $10 \mathrm{kN}$ and $26 \mathrm{kN}$ respectively.

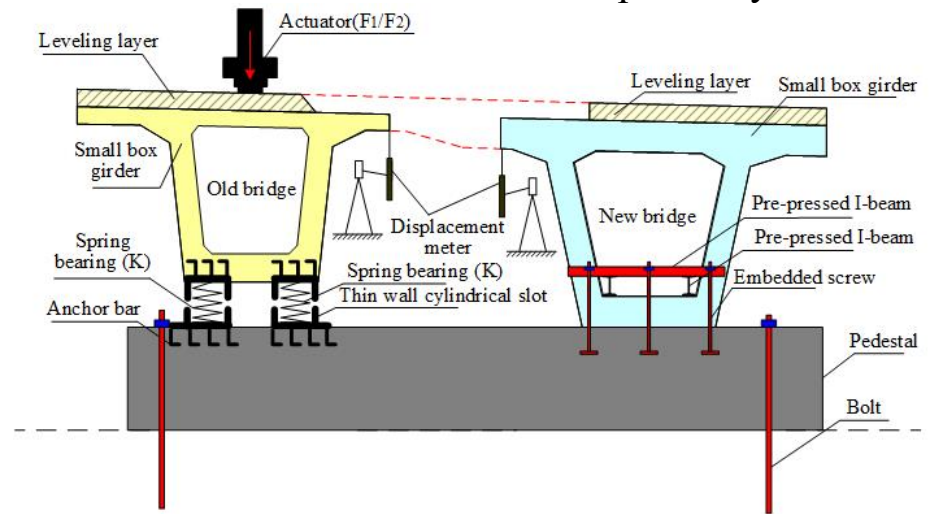

Fig. 7 Overall layout of full scale segmental model

Numerical simulation and experimental curve of displacement on both sides of joint are depicted in Figure 8. According to the development model of concrete elastic modulus, the displacement of joint on old bridge side decreases rapidly, reaches $0.53 \mathrm{~mm}$ after 8 hours and gradually tends to be stable. On the contrary, the displacement of joint on new bridge side increases rapidly in the first 4 hours, then slowly increases to $0.27 \mathrm{~mm}$ and remains unchanged. The 
displacement of the new bridge side changes abruptly from $0.33 \mathrm{~mm}$ to $0.25 \mathrm{~mm}$ while the construction framework is removed after 40 hours, and then the displacement increases slightly, and finally tends to be stable. In the first 22 hours, the obvious change of the displacement is attributed to the slow development of the actual elastic modulus of concrete and the influence of dynamic deflection.
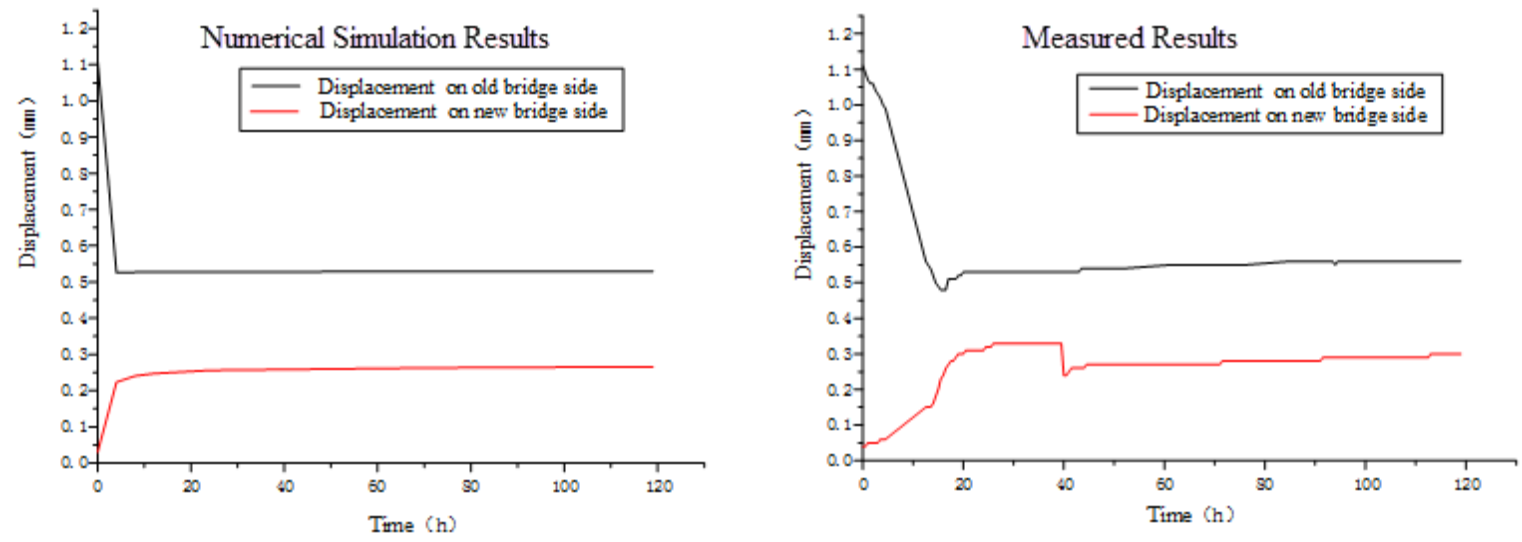

Fig. 8 Displacement curve on both sides of joint

The comparison between measured and calculated deflection difference curves on both sides of joint is displayed in Figure 9.

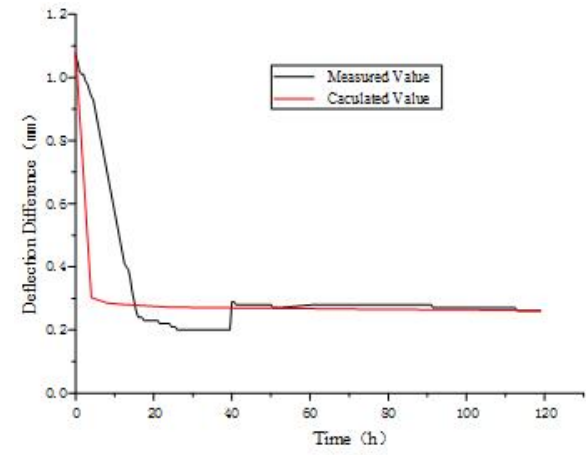

Fig. 9 Comparison of deflection on both sides of joint

The top reinforcement of the joint is in tension and the bottom reinforcement is under compression. It could be observed from Figure 10 that the calculated strain of reinforcement at the top and bottom of the joint is quite consistent with the measured value in the early stage. After the concrete age for 1-day, the measured value is smaller than the calculated value.
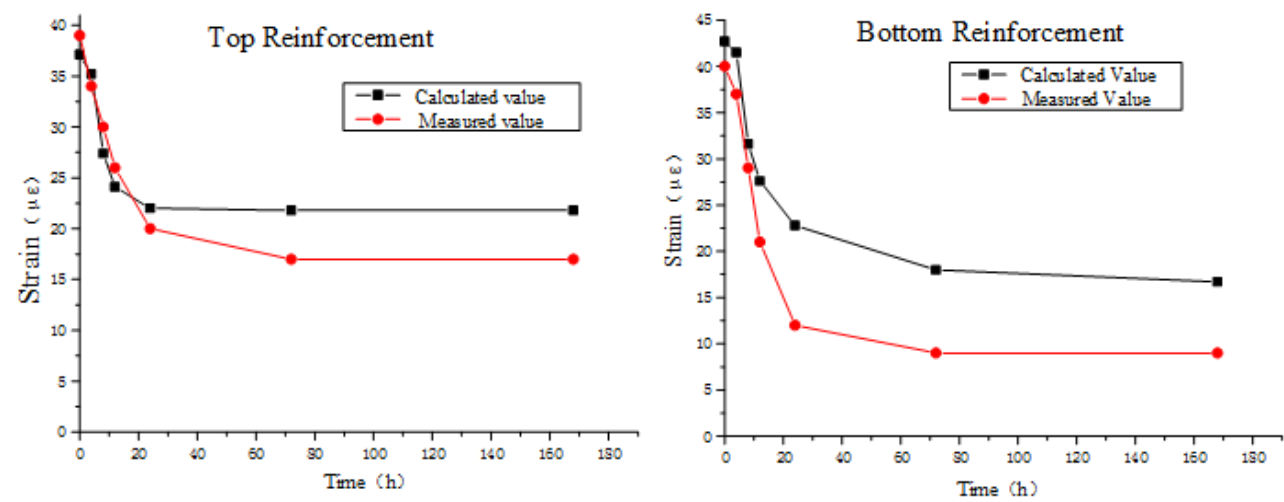

Fig. 10 Strain of reinforcement of the joint 


\section{Research on Shear Transfer Mechanism and Ultimate Bearing Capacity of Concrete Joint in Segmental Model}

Research on Shear Transfer Mechanism

Elastic modulus of concrete (Eq.1) was determined according to the regulation CEB-FIP MC90 as below:

$$
E_{c}(t)=E_{c} \cdot \exp \left(0.5 s\left[1-(28 / t)^{0.5}\right]\right)
$$

Where: $E_{c}-$ Elastic modulus of concrete at 28 days of age

$s$ - Coefficient of cement type. This value is 0.2 for fast setting high strength cement, 0.25 for wing plate cement, and 0.38 for retarded cement.

$t$-Days after concrete casting.

In ABAQUS finite element model, the elastic modulus value of joint concrete is given with the development of age, and the growth trend of shear force of joint concrete of whole and segment test models with curing age is calculated and analyzed. The shear transfer value of concrete joint at $1 \mathrm{~m}$ section at the mid-span is taken for the overall model, which could accurately reflect the stress state of the whole structure. It can be seen from Figure 11 that the shear transfer rate of the whole and segment model joints is very fast in the early stage, and then gradually tends to be stable.

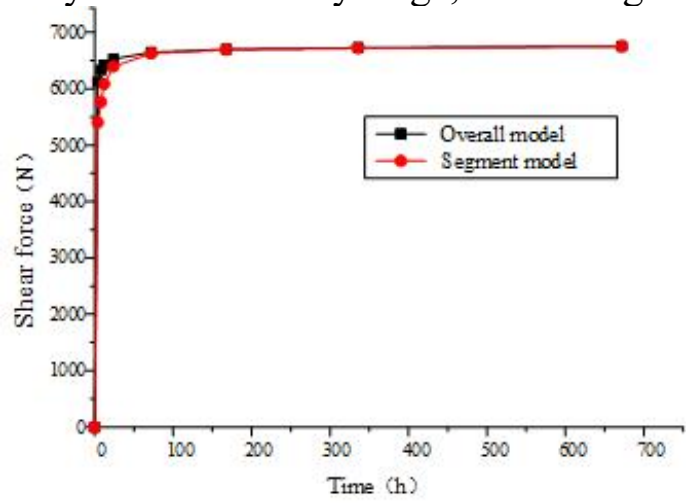

Fig. 11 Shear transfer curve of overall and segment models

\section{Research on Ultimate Bearing Capacity}

The plastic damage model of concrete is used to calculate the ultimate bearing capacity level of the full-scale segment test model. The peak point of the force-displacement curve is taken as the failure point of the component, and all the joint reinforcement reaches the yield strength. The loading actuator is deployed at the chamfering of the box girder side of the old bridge on the top of the joint, which is the weakest position of the structure.

As illustrated in Figure 12, the yield stress and inelastic strain curve of C50 concrete in compression stage, as well as the yield stress and cracking strain curve in tension stage, are derived respectively, which is the failure criteria of concrete constitutive relation.
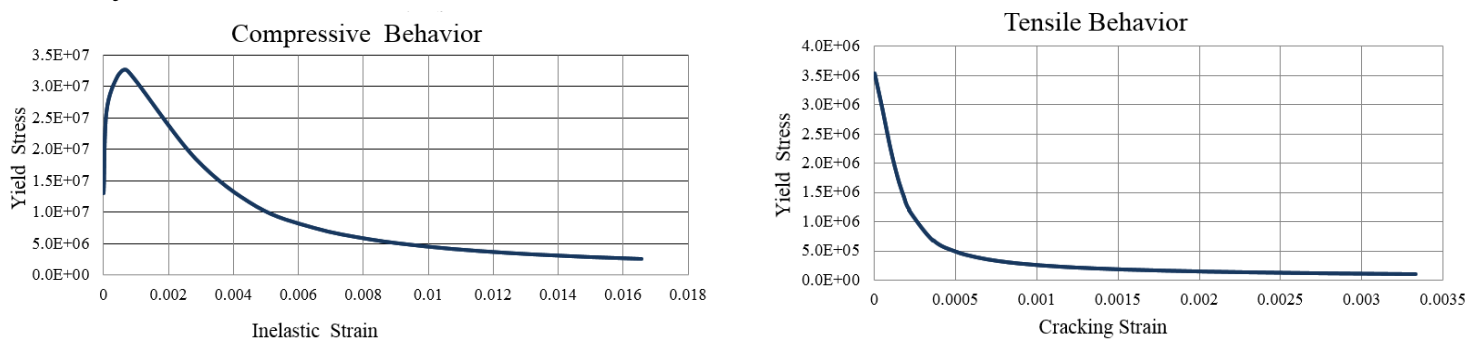

Fig. 12 Failure criterion of concrete 
Failure model adopts the displacement convergence standard, and the increment step size is set to 0.001 . Then the damage factors of compression and tension are calculated, which are denoted as $d_{c}$ (Eq.2) and $d_{t}$ (Eq.3) respectively:

$$
d_{c}=1-\frac{\sigma_{c} E_{0}^{-1}}{\varepsilon_{c}^{p l}\left(1 / b_{c}-1\right)+\sigma_{c} E_{0}^{-1}}
$$

Where: $b_{c}=\varepsilon_{c}^{p l} / \varepsilon_{c}^{i n}$.

$$
d_{t}=1-\frac{\sigma_{t} E_{0}^{-1}}{\varepsilon_{t}^{p l}\left(1 / b_{t}-1\right)+\sigma_{t} E_{0}^{-1}}
$$

Where: $b_{t}=\varepsilon_{t}^{p l} / \varepsilon_{t}^{c k}$.

The monotonic load displacement curve of solid model simulation test component is shown in Figure 13. When the loading force increases from zero to $790 \mathrm{kN}$, the slope of the curve remains unchanged, and the stress of concrete is basically in the elastic stage. Meanwhile, the tensile strain at the bottom of the joint concrete could reach the cracking value, a small number of microcracks appearing, and the tensile stress at the bottom of the joint is mainly borne by the reinforcement. When approaching the yield point, a small amount of plastic deformation could occur. Besides, the deflection curve is slightly concave, in the meantime, the cracks would continue to extend and develop. When the loading capacity increases to $1190 \mathrm{kN}$, the reinforcement at the bottom of the joint would reach the maximum strength, the concrete cracks would develop rapidly, and the bearing capacity of the structure would decrease rapidly.

Referring to the standard load of 55T heavy vehicle, the load of rear axle is $140 \mathrm{kN}$, and the weight of one side wheel is $70 \mathrm{kN}$. Therefore, the most unfavorable position of joint is fully able to bear 17 times of 55T heavy vehicle wheel load, i.e., the widening measures are reliable.

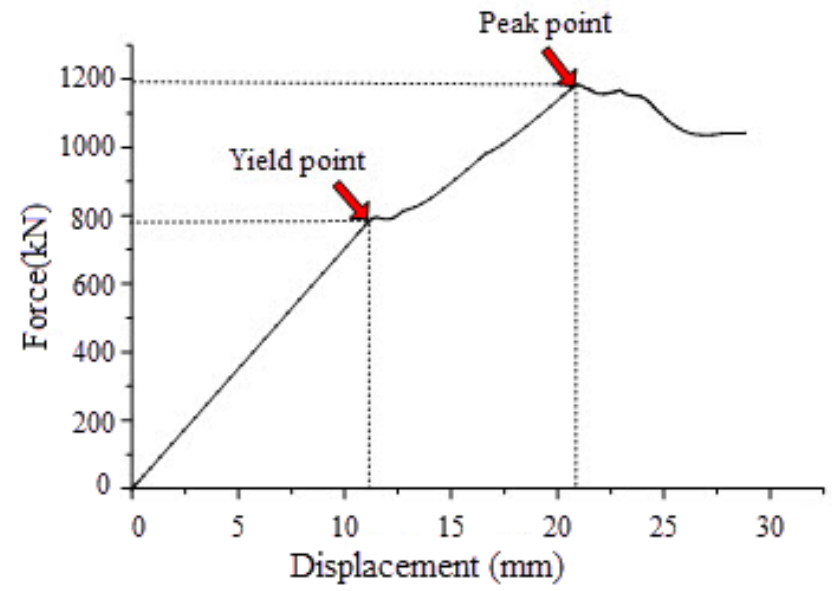

Fig. 13 Load-displacement curve of full scale segment model

\section{Summary}

In this paper, through the full-scale segment test model, the deflection difference on both sides of the joint and the strain of the joint reinforcement are simulated and compared with the experimental data, which verifies the reliability of the three-dimensional solid finite element model, and could accurately calculate the joint shear transfer value and monotone loading curve. Through the above research and analysis, it could be summarized that: 
(1) The early strength of concrete develops rapidly, and the deflection difference decreases rapidly. The maximum decrease of deflection difference is $27 \%$ one day before casting, and remains unchanged after casting.

(2) Based on the calculation and analysis of the development of the shear force of the joint concrete of the whole and section test models with the curing time, it is concluded that the shear transfer of the joint concrete develops rapidly in the early stage, and then gradually tends to be stable, and the segment model could accurately reflect the stress state of the whole structure.

(3) The load-displacement curve of the full-scale segment test model is obtained. The most unfavorable position of the joint is fully able to bear 17 times of 55T heavy vehicle wheel load, and the measures are reliable.

(4) The deflection difference is an important index to reflect the performance of widening bridge. The mid-span deflection difference should be monitored during the construction and operation stage. The maximum stress of the joint concrete appears near the beam end support, so monitoring points should be considered.

\section{References}

[1] Xuejun Wang, Jinsheng Du, et al. Discussion on Several Problems in Bridge Widening of Freeway [J]. Highway, 2008 (7): 169-174.

[2] Wei Li. Key Technology of Shenyang to Dalian Freeway Extension Project [C]. On 2006 National Freeway Reconstruction and Expansion Technology Seminar, 2006.

[3] MA Chun-sheng, SONG Shen-you. Design of Connection Bewteen New Beam and Old One of Huzhou Bridge on Guangfo Freeway [J]. Highway, 2003 (8): 63-66.

[4] Yande Gui. Discussion on Design Method of Freeway Widening [J]. Highway, 2004 (7): 59-64.

[5] Hua Bin, Li Jie, et al. Research on the Key Widening Technology for PC Bridge [J]. Modern Transportation Technology, 2006 (5): 72-77.

[6] Qingjie Wen, Jianshu Ye. Analysis of Shrinkage and Creep Effect in Widening Reinforced Concrete Girder [J]. Journal of Southeast University, 2006, 36 (4): 596-600.

[7] Industry Standard of Ministry of Transport. General Specifications for Design of Highway Bridges and Culverts [S]. Beijing: China Communications Press, 1989. 